\title{
The Roles and Responsibilities of Pharmacovigilante's in Adverse Drug Reaction Monitoring Centre
}

\author{
Rajalakshmi Rukmangathen ${ }^{*}$, Brahmanapalli Vasundara Devi², Dharini Bhoopathi ${ }^{3}$ \\ ${ }^{1,2}$ Adverse Drug Reaction Monitoring centre, Department of Pharmacology, Sri Venkateswara Medical College, Tirupati, Tamil Nadu, \\ INDIA. \\ ${ }^{3}$ Adverse Drug Reaction Monitoring centre, SDS Tuberculosis Research Centre \& Rajiv Gandhi Institute of Chest Diseases, Bengaluru, \\ Karnataka, INDIA.
}

\begin{abstract}
Pharmacovigilante's (PVLs) are highly trained, extra committed, dedicated professionals acting as the main link between patients and other healthcare professionals for better outcome in promoting safety of drugs. The process of drug safety monitoring and its outcomes will not only improve patient's quality of life, but will also help in bringing changes in policies related to healthcare economics and other issues of national importance. National and regional Pharmacovigilance (PV) systems are well-adapted bodies, attuned to the intricate collection and analysis of ADR data that leads to timely alerts and interventions to protect population health. The adverse events reported by PVLs to PV system will potentially benefit to the community due to their proximity to both the population and public health practitioners. This article overviews the functions of PVLs in the context of their roles and responsibilities in the Pharma-covigilance Programme of India working in an adverse drug reaction monitoring centre (AMCs) mainly focusing on promotional activities of PVPI.
\end{abstract}

Key words: Pharmacovigilante's, Pharmacovigilance Programme of India, Adverse drug reactions, Patient safety, Adverse drug reaction monitoring centre.

\section{INTRODUCTION}

The Central Drugs Standard Control Organisation (CDSCO), New Delhi holds the pride of initiating a nation-wide pharmacovigilance programme under the aegis of Ministry of Health \& Family Welfare, Government of India. Indian Pharmacopoeia Commission (IPC), located at Ghaziabad is functioning as National Coordination Centre (NCC) for Pharmacovigilance Programme of India (PvPI) since $15^{\text {th }}$ April 2011. ${ }^{1}$ PVPI was launched with a wider objective to safeguard the health of 1.28 billion people of India. In the initial days, under this National programme, All India Institute of Medical Sciences, New Delhi was the National Coordination Centre (NCC). ${ }^{2}$ PVPI has survived the danger of infant mortality and it has completed 5 years and now it would grow as a healthy child to benefit the nation. ${ }^{3}$ The NCC is operating under the supervision of Steering Committee to recommend procedures and guidelines for regulatory interventions in India. National and regional Pharmacovigilance (PV) systems are well-adapted bodies, attuned to the intricate collection and analysis of ADR data that leads to timely alerts and interventions to protect population health. ${ }^{4}$

It is a known fact that no drug is completely free from side effects. It has been reported that the number of patients dying because of contrary effects of drugs per year increased up to 2.6-fold. Moreover, rates of hospitalization of patients are increasing owing to adverse effects of drugs. ${ }^{5}$ Therefore, steps are taken to control the adverse effect of drugs. According to World Health Organization
DOI: 10.5530/ijopp.10.2.28

Address for correspondence: Rajalakshmi R, Pharmacovigilance Associate, Department of Pharmacology, Sri Venkateswara Medical College,

Tirupati, Tamil Nadu, INDIA. Phone no: 9985795730

E-mail: rrajalakshmi2002@ yahoo.co.in 
(WHO), Pharmacovigilance is a set of practices aiming at the identification, understanding and assessment of risks associated with drugs. Membership of the WHO Programme for International Drug Monitoring is co-ordinated by the WHO Collaborating Centre for International Drug Monitoring, known as the Uppsala Monitoring Centre (UMC).

Pharmacovigilance starts from the pre-marketing of new drugs and continues through the post-marketing of drugs. ${ }^{6}$ To collect the adverse drug reactions (ADRs) from patients, ADRs monitoring centers (AMCs) are set up under NCC. The rationale for setting up the AMCs is to make it possible to identify rare ADRs that could not be found through clinical trial programmes. ${ }^{7}$ The spontaneous reporting of ADRs is considered as the foundation of post marketing surveillance of drug safety. The main function of spontaneous reporting is the early detection of signals of new, rare and serious ADRs. ${ }^{8}$

\section{The purpose of Pharmacovigilance}

Pharmacovigilance is the science and activities relating to the detection, assessment, understanding and prevention of adverse effects or any other possible drug-related problems. Recently, its concerns have been widened to include: herbals, traditional and complementary medicines, blood products, biological, medical devices, and vaccines., 10

Many other issues are also of relevance to the science: ${ }^{11}$

- Medication errors

- Lack of efficacy reports

- Substandard, abuse and misuse of medicines

- Use of medicines for indications that are not approved and for which there is inadequate scientific basis

- Case reports of acute and chronic poisoning

- Assessment of drug-related mortality

- Adverse interactions of medicines with chemicals, other medicines, and food.

The major functions of NCC are to collect, collate and analyze Adverse Drug Reactions (ADRs) data and to recommend regulatory interventions to Central Drugs Standard Control Organization (CDSCO). Also communicates the risks to healthcare professionals and the public through PvPINewsletters. ${ }^{12}$ NCC provides the logistic support and manpower to AMCs for their smooth functioning and reporting the ADRs.

\section{Procedure for the Selection of AMC}

To participate in this nationwide programme and to monitor drug safety, a 'Letter of Intent' is required to be submitted by the Head of the Institutions. After examining the suitability, the concerned centre may be inducted as AMCs under PvPI. Subsequently NCC communicates the AMC details to WHO-Uppsala Monitoring Centre (UMC), Sweden to obtain VigiFlow (WHO-UMC owned online software) login details to upload ADRs. ${ }^{13}$

\section{Status of AMC}

At present 250 AMCs are engaged to monitor and report ADRs to NCC. AMCs of PvPI are located from Kashmir to Kanyakumari. AMCs are established in 29 states and 4 union territories. ${ }^{3}$ Each AMC under PvPI is assigned with a coordinator (Department of Pharmacology) and Patient Safety Pharmacovigilance Associate responsible for its functioning. ${ }^{13}$ These AMCs are responsible for col $\neg$ lecting adverse event as per Standard Operating Pro $\neg$ cedure (SOP), as well perform follow up if required for the completeness of ADR reports. These drug safety information/Individual Case Safety Reports (ICSRs) are collected in predesigned suspected ADR reporting form, broadly consist of 4 sections i.e., patient's information, suspected adverse reaction, suspected medication(s), and reporter's information. ${ }^{14}$ Information provided in this form is handled in strict confidence. These ICSRs are then reported to NCC for Quality \& Signal Review via Vigiflow, a web-based ICSRs management system that is specially designed for use by the authorized national centres in the WHO Programme for International Drug Monitoring after causality assessments of ADRs performed using the WHO-UMC causality assessment system. ICSR data can be manually entered via VigiFlow with support from the latest versions of terminologies such as the WHO Drug Dictionary and WHO-Adverse Reaction Terminologies. All the Pharmacovigilance Associates have undergone training on the elements of pharmacovigilance and filling ADR form and uploading the data on the vigiflow. All the coordinators of the AMCs are enthusiastically contributing and supporting the program which is evident from the monthly progress report of the AMCs under PvPI.

At present, teaching and corporate hospitals have been identified as AMCs under PvPI. The other healthcare institutes associated with patients care by providing safe and effective medication should be encouraged for ADR reporting. Beside these, pharmaceutical companies need to be involved in PvPI for better pharmacovigilance system. Furthermore,

Indian Journal of Pharmacy Practice, Vol 10, Issue 2, Apr-Jun, 2017 
incorporating a chapter on pharmacovigilance in education curriculum of medicine, pharmacy, nursing etc. could generate the culture of ADR reporting among young scholars. ${ }^{15}$ In future Pharmacy institutions may be enrolled in PvPI to enhance ADRs reporting. NCC is closely working with the AMCs to coordinate with nearby Pharmacy institution in reporting of ADRs. ${ }^{13}$ National Coordination Centre, IPC has included Haemovigilance, Biovigilance and Materiovigilance in pharmacovigilance program.

\section{Pharmacovigilante's Qualities and skills in PvPI:16,17}

The professionals engaged in Pharmacovigilance activities are termed Pharmacovigilante's (PVLs). PVLS are highly trained, extra committed, dedicated and specialized professionals acting as the main link between patients and other healthcare providers for better outcome in promoting safety of drugs. The PVLs need a degree in medicine, dentistry, pharmacy, nursing, life sciences or other health related field or equivalent qualification to conduct PV activities. They co-ordinate with maximum number of stakeholders such as doctors, pharmacists, nurses, patients, regulators and media etc.

- Know the ethics and good Pharmacovigilance (PV) practices

- Have basic knowledge of concepts, methodologies of PV, drug regulation etc.

- Competant enough to handle the issues like case narrating and processing, causality assessment, identifying new signals, benefit risk assessment.

- Have to be vigilant round the clock because ADRs to the patients cannot be expected to occur only during working hours.

- Command over management and organizational skills

- They are required to be updated with national and international legislations.

- Updated with newer technologies to reach out the messages in rapid and effective way.

- Create professional bonding with the stakeholders

- Maintain mutual relationship with the colleagues and similarly placed organizations (both national and international)

- Provide innovative ideas in PV

How and whom to report ADR ${ }^{18}$
Suspected ADR forms will be available at all nursing stations of the hospital/ ADR forms can be downloaded from www.ipc.gov.in

Healthcare professionals can fill the "Suspected Adverse Drug Reaction Reporting Form" /and consumers can fill the consumers side effects form and send it to nearest the Adverse Drug Reaction Monitoring Centre (AMC), (list of nationwide AMCs is available at http://www.ipc.gov.in, http://www. ipc.gov.in/PvPI/pv_home.html) or directly to the National Coordinating Centre (NCC). You can directly mail the form to pvpi@ipcindia.net oripclab@vsnl.net.

Fill the Suspected ADR form/ consumer's side effects form (available in vernacular languages which can be downloaded from ww.ipc.gov.in) and drop into ADR notification box, installed near the key places of the hospital.

Toll free helpline (1800-180-3024) number can also be used to directly report an ADR.

Android mobile application is used for instant ADR reporting to PvPI (download ADR app from Google play store \& report ADRs anywhere, anytime).

\section{Mobile App for ADR reporting An Effective Tool}

India is cementing its place IT sector through mobile connections to reach every individual in a population of 1.28 billion where approximately $77.58 \%$ population is already using mobile phones. Hence it is more rationale to introduce the concept of PvPI to stake holders via mobile phones. Shri B P Sharma, Secretary Health, Ministry of Health \& Family Welfare and Chairman, Indian Pharmacopoeia Commission, Government of India on 22 ${ }^{\text {nd }}$ May, 2015 launched an Android Mobile Applications for Adverse Drug Reactions (ADRs) reporting facility to the stakeholders of Pharmacovigilance Programme of India (PvPI). The Mobile Application for ADR Reporting is a joint venture of the Indian Pharmacopoeia Commission, National Coordination Centre for Pharmacovigilance Programme of India and NSCB Medical College, Jabalpur. The Mobile Application is expected to provide a platform for the private healthcare professionals to report ADRs to safeguard and enhance public health by ensuring the safety, efficacy and quality of drugs. The Application has in-built facilities and features for reporting of Adverse Drug Reactions such as customization of reporter details, auto entry in drug details WHO algorithm based causality assessment etc Hence Android mobile application is used for instant ADR reporting to PvPI (download ADR app from Google play store \& report ADRs anywhere, anytime. 


\section{Programme communications}

The ADRs will be sent to WHO-Uppsala Monitoring Centre (UMC) for analysis and signal detection. Simultaneously ADRs are evaluated at NCC and the inferences are used to recommend regulatory body i.e. CDSCO to take necessary regulatory interventions, besides communicating risks to healthcare professionals and the public. Prompt recognition, early detection and intervention may reduce: morbidity, mortality, unnecessary investigations, treatment, human suffering and health care cost. Programme communications is depicted in Figure 1.

Promotional activities on PvPI carried out by a Pharmacovigilante's in AMCs
NCC-PvPI is taking several initiatives to expand its outreach to the urban, rural and every corner of the country to ensure the safety of medicines. In this regard, the Adverse Drug Reaction Monitoring Centres (AMCs) under PvPI are playing vital role to disseminate the concept of PvPI to the healthcare professionals and general public. In addition to this, Several AMCs are also voluntarily contributing to the programme by enhancing their ADR reporting system as an ethical responsibility. To create awareness of PvPI among public and healthcare professionals and to strengthen the ADR reporting system, the following promotional activities can be carried out in AMC.

Helpline number (Tollfree) of PvPI can be incorporated on the outpatient departments

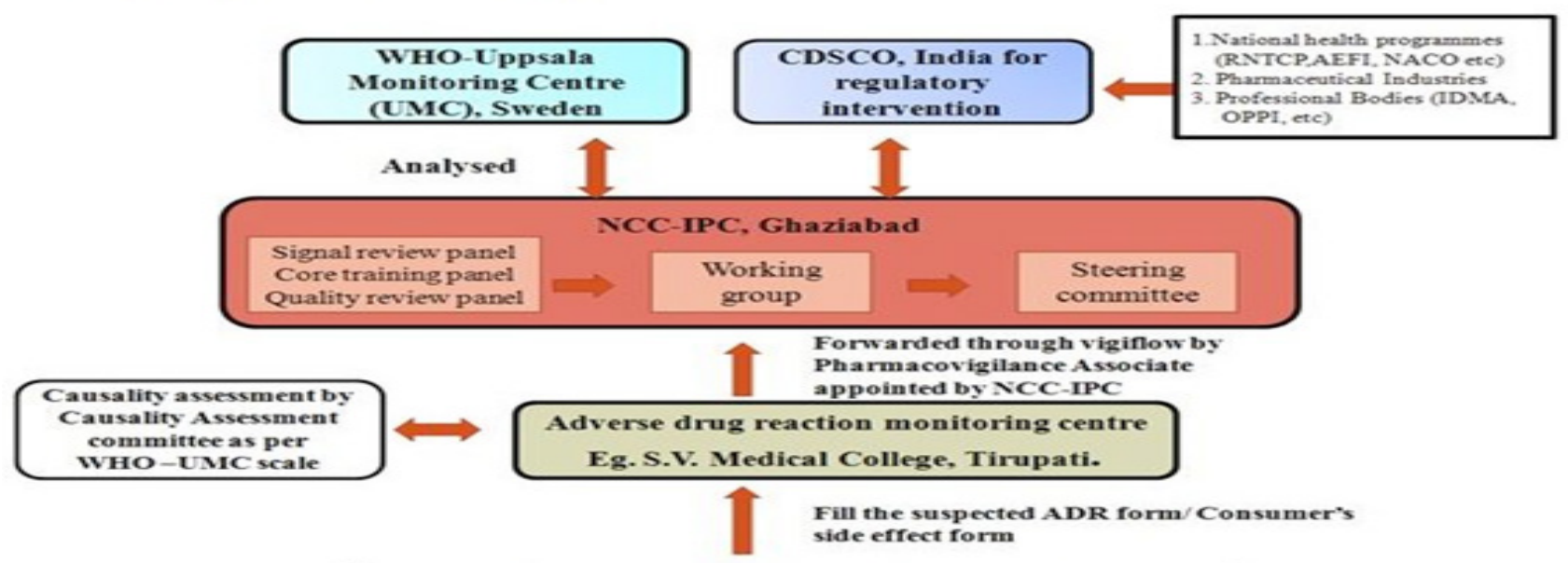

Doctors, Dentists, Nurses, Pharmacists, other healthcare and non healthcare professionals including consumers. Pharmaceutical industry etc.

Figure 1: Programme Communications.

(OPD) and inpatient department (IPD)forms/hospital prescription.

Audio-Visual slides of PvPI can be displayed in the main hospital premises.

ADR Reporting form may be provided along with the file in Inpatient departments

(IPDs).

Display PvPI posters in English and vernacular language, at various key places. Viz. Casuality, Intensive care units (ICU), OPDs, inpatient departments (IPDs), Pharmacy, corridors and canteen of the hospital to sensitize ADR reporting.

Display posters/ Pamphlets to sensitize ADR reporting via android mobile app.
Distribution and display of ADR awareness calendars in working cabin of all healthcare professionals and key places of hospital.

Organizing internal CME/Workshops/seminars/ awareness lectures on PvPI periodically.

Promoting PvPI by association with Pharmacy Institutes and other paramedical colleges.

Organize orientation programmes on Pharmacovigilance for Health care professionals, Post graduates, under graduate medical students, Dental, Nursing and other paramedical students etc. Highlighting the importance, their role of ADR reporting, and also hands on training on reporting through android app $\&$ filling the suspected ADR form.

Installation of Adverse Drug Reaction Drop boxes at various key places of the hospital viz. ICU's, 
Casuality, Inpatient departments and outpatient departments.

Sensitization of peripheral / corporate hospitals and colleges

Advertisement of PvPI toll free number \& android mobile app through media (Newspaper/

Internet/).

Creating a Social media (i.e Whatsapp/Facebook) group involving HCP's for updating on new and existing safety data .

Sending regular feedback Feedback information on hospital pharmacovigilance activities should be made available to health care providers' e.g. periodic summary of reported ADRs in hospital, periodic summary of specific type of ADR and information about ADR warnings and thank you card for ADRs reported.

Create a webpage for PvPI in the college website.

\section{CONCLUSION}

Pharmacovigilance activities are expanding around the world. This is reflected in the increasing number of AMCs in India that have been established from Kashmir to Kanyakumari in recent years. The effectiveness of national pharmacovigilance activities is directly dependent on the active participation of Government and health care professionals at all levels (doctors, dentists, physiotherapists, pharmacists, nurses) which makes the program a success. PVLs of PvPI are proud of entering the noble and fulfilling the wonderful profession of PV and for being a partner in public health, by doing best for the prevention of ADRs. The hard work, sheer determination, dedication and sincerity of the professionals have brought this programme at par with global standards.

\section{ACKNOWLEDGMENT}

We thank Principal, Sri Venkateswara Medical College, Tirupati. We also express our sincere thanks to NCC-PvPI, Indian Pharmacopoeia Commission for giving their support and encouragement.

\section{CONFLICTS OF INTEREST}

Nil

\section{ABBREVIATIONS USED}

PVLs: Pharmacovigilante's; PV: Pharmacovigilance; ADR: Adverse drug reaction; AMC: Adverse drug reaction monitoring centre; CDSCO: Central Drug Standard Control Organization; PVPI: Pharmacovigilance Programme of India; NCC: National Coordination centre; HCP: Health care Professional; ICSR: Individual Case Safety Report; ICU-Intensive care unit; WHO: World Health Organisation; UMC-Uppsala Monitoring Centre; CME: Continuing Medical Education; IPD: In Patient Department; OPD: Out Patient Department; SOP: Standard operating procedure.

\section{REFERENCES}

1. Kalaiselvan V, Prakash J, Singh GN. Pharmacovigilance Programme of India. Archives of Pharmacy Practice. 2012;3:229-32.

2. Rehan HS. Tamil Nadu J. Veterinary \& Animal Sciences. 2013;9:417-20.

3. Pharmacovigilance Programme of India (PvPI). Newsletter. 2016;6(15):1-4.

4. Gupta $Y$, Ensuring Patient Safety Launching the new Pharmacovigilance programme of India. Pharma times. 2010;42(8).

5. Sahu RK, Yadav R, Prasad P, Roy A, Sahu SC, et al. Adverse drug reactions monitoring: prospects and impending challenges for pharmacovigilance. Springer Plus. 2014;3(1):695.

6. Lazarou J, Pomeranz BH, Corey PN. Incidence of adverse drug reactions in hospitalized patients-a meta-analysis of prospective studies. The Journal of the American Medical Association. 1998;279(15):1200-5.

7. Olsson S. The role of the WHO Programme on International Drug Monitoring in coordinating worldwide drug safety efforts. Drug Safety. 1998;19(1):1-10.

8. Kalaiselvan V, Prasad T, Akanksha B, Singh S, Singh GN. Adverse drug reactions reporting culture in Pharmacovigilance Programme of India. Indian Journal of Medical Research. 2014;140(4):563-4.

9. Meyboom RHB, Egberts ACG, Gribnau FWJ, Hekster YA. Pharmacovigilance in perspective. Drug Safety. 1999;21(6):429-47.

10. Abbing HDCR. Legal aspects of medical devices: Study on regulatory mechanisms for safety control. Health Services Research. IOS Press. 1993:358-61.

11. Pharmacovigilance programme of India, PvPI Newsletter. 2011;1(1):1-8.

12. Kalaiselvan V, Prasad $T$ and Singh A. Current Status of Adverse Drug Reactions Monitoring Centres under Pharmacovigilance Programme of India. Indian Journal of Pharmacy Practice. 2014;7(3):19-22.

13. Kalaiselvan V, Sharma S, Singh GN. Adverse reactions to contrast media: an analysis of spontaneous reports in the database of the pharmacovigilance programme of India. Drug Safety. 2014;37(9):703-10.

14. Lihite RJ, Lahkar M. An update on the Pharmacovigilance Programme of India. Frontier Pharmacology. 2015;6:194.

15. Pharmacovigilance programme of India (PVPI) Newsletter. 2015;5(12):3-4.

16. Kalaiselvan V, Prasad T, Vijay Venkatraman J, Singh GN. Pharmacovigilante's in the Pharmacovigilance Programme of India: Ideal Qualities and Skills. Journal Young Pharmacists. 2016;8(3):291-292.

17. www.pharmabiz.com/NewsDetails.

18. www.ipc.gov.in

19. Inder D, Kumar PJ. Pharmacovigilance in India: A Rising Concern towards Safe Medication Use. Journal of Advanced Research in Medicine. 2015;2(3). 